\title{
A influência de uma grande mineradora sobre o comportamento estratégico de uma pequena empresa localizada no interior de Minas Gerais: Um estudo de caso sobre os impactos na Gestão de Saúde e Segurança Ocupacional
}

\author{
The influence of a large mining company on the strategic behavior of a small company located in
} the interior of Minas Gerais: A case study on the impacts on Occupational Health and Safety

\section{Management}

\section{La influencia de una gran empresa minera en el comportamiento estratégico de una pequeña} empresa ubicada en el interior de Minas Gerais: Un estudio de caso sobre los impactos en la Gestión de Seguridad y Salud Ocupacional

\begin{abstract}
Resumo
Este artigo tem como objetivo investigar a influência de uma mineradora de grande porte sobre a gestão da Saúde e Segurança Ocupacional (SSO) em uma pequena empresa terceirizada que fornece serviços de fabricação de implementos rodoviários, manutenção e higienização de veículos diversos. Para isto, utilizou-se a metodologia de estudo de caso com o propósito de analisar de forma aprofundada tal influência. A pesquisa foi dividida em três fases, sendo elas a coleta de dados, análise e apresentação dos resultados e redação do relatório. Os resultados indicam que houve grande influência da empresa mineradora sobre as questões relativas à gestão de SSO. Esta influência pôde ser evidenciada por meio de mudanças internas na empresa terceirizada, principalmente com relação ao aumento de investimentos e ampliação do comprometimento com a saúde e segurança ocupacional. Estas mudanças foram motivadas por exigências contratuais estabelecidas entre elas, as quais extrapolam simples preocupações com requisitos legais vigentes no país.
\end{abstract}

Palavras-chave: Saúde e segurança ocupacional; Terceirização; Pequenas empresas; Gestão de saúde e segurança.

\begin{abstract}
This paper aims to investigate the influence of a large mining company on the management of Occupational Health and Safety (HSO) in a small outsourced company that provides road implement manufacturing services, maintenance and sanitation of various vehicles. For this, the case study methodology was used in order to analyze in depth such influence. The research was divided into three phases, with are data collection, analysis and presentation of results, and report writing. The results indicate that there was a great influence of the mining company on issues related to HSO management. This influence could be highlighted through internal changes in the outsourced company, mainly in relation to the increase in investments and expansion of the commitment to occupational health and safety. These changes were motivated by contractual requirements established between them, which go beyond simple concerns with current legal requirements in the country.
\end{abstract}

Keywords: Occupational health and safety; Outsourcing; Small business; Health and safety management.

\section{Resumen}

Este artículo tiene como objetivo investigar la influencia de una gran empresa minera en la gestión de la Seguridad y Salud Ocupacional (SSO) en una pequeña empresa subcontratada que brinda servicios de fabricación de implementos viales, mantenimiento y saneamiento de diversos vehículos. Para ello, se utilizó la metodología de estudio de casos con 
el fin de analizar en profundidad dicha influencia. La investigación se dividió en tres fases, a saber, recopilación de datos, análisis y presentación de resultados y redacción de informes. Los resultados indican que hubo una gran influencia de la empresa minera en temas relacionados con la gestión de SSO. Esta influencia podría evidenciarse a través de cambios internos en la empresa subcontratada, principalmente en relación al aumento de inversiones y ampliación del compromiso con la seguridad y salud ocupacional. Estos cambios fueron motivados por requisitos contractuales establecidos entre ellos, que van más allá de las simples preocupaciones con los requisitos legales vigentes en el país.

Palabras clave: Salud y seguridad ocupacional; Externalización; Pequeña empresa; Gestión de seguridad y salud.

\section{Introdução}

A terceirização tem sido largamente adotada pelas grandes empresas do ramo da mineração desde a década de 1990 (King, 2005). Focando-se na competitividade e maior produtividade, as organizações passaram a centralizar os seus recursos no produto estratégico e repassar a terceiros a execução de serviços complementares e especializados (Ceribeli \& Lima,2019).

$\mathrm{Na}$ gestão das organizações mineradoras, a terceirização já se tornou uma prática associada ao processo produtivo, o que implicou em uma reestruturação na forma como é feita sua administração. Esta reestruturação transformou processos considerados como atividades-meio, executados por pessoal próprio, em atividades-fim, delegadas às empresas terceirizadas (Saraiva \& Silva,2020). Esta prática foi vista como uma estratégia de redução de custo e racionalização do trabalho, inviabilizando a estrutura totalmente verticalizada e direcionando as organizações mineradoras para a horizontalização (Magalhães, Carvalho Neto, \& Gonçalves, 2010).

Diante do avanço da terceirização, as empresas de pequeno porte inseridas na região mineradora do interior de Minas Gerais perceberam que a prestação de serviços para as grandes empresas seria uma estratégia de sobrevivência e crescimento diante de um mercado desafiador (Rabelo, 2014). No entanto, tais empresas necessitam se adequar aos padrões exigidos pelas contratantes para o desenvolvimento dos serviços contratados.

$\mathrm{Na}$ ótica das pequenas empresas terceirizadas, coexistem em seu portfólio uma multiplicidade de contratos, cada um com seu grau de complexidade e peculiaridades. Estas peculiaridades envolvem, entre outros, questões previdenciárias, trabalhistas, tributárias, requisitos técnicos, de segurança do trabalho e ambiental, que acabam por exigir destas organizações uma gestão efetiva, baseada em ferramentas de controle para a garantia de desempenho adequado (Magalhães, Ferreira, Saraiva \& Brasil, 2009)

Conforme aponta Guerra e Teixeira (2010), as pequenas empresas possuem características próprias, diferenciando-se das grandes empresas não apenas em tamanho, mas em termos estruturais e organizacionais; simultaneamente, apresentam grande heterogeneidade entre si. Essa heterogeneidade é identificada, principalmente, em termos de capacidade inovativa, havendo diferenças também quanto às questões organizacionais e capacidade de alavancar os negócios.

Dentre as particularidades em relação às empresas de grande porte, estão a limitada base de recursos (financeiros, humanos, técnicos, tecnológicos e de gestão), a cultura organizacional singular e a menor capacidade de influenciar as relações com o ambiente externo, o qual inclui clientes, fornecedores e mercado de trabalho (Costa \& Menegon, 2008). Em compensação, destaca-se como vantagens em relação às grandes empresas, a grande capacidade de absorção da mão-de-obra a baixo custo, com menores exigências de qualificação e a alta flexibilidade (Guerra \& Teixeira, 2010).

Outro aspecto relevante nessa comparação é que, no que se refere à Saúde e Segurança Ocupacional (SSO). Todas as empresas devem cumprir obrigações e princípios de prevenção semelhantes, independentemente do porte (Arocena \& Núñez, 2010). As empresas menores estão sujeitas a um tratamento diferenciado na lei, quando estas possuem um número pequeno de empregados ficam isentas de constituírem um Serviço Especializado em Engenharia de Segurança e em Medicina do Trabalho (SESMT) e em alguns casos de formar a Comissão Interna de Prevenção de Acidentes (CIPA), com representantes eleitos pelos trabalhadores. Grandes empresas normalmente possuem maiores exigências legais e possuem um grau de maturidade de saúde e segurança no trabalho mais elevado do que as de pequeno porte, motivados por seus sistemas de gestão mais complexos 
(Gonçalves Filho, Andrade \& Marinho, 2011). No que tange à legislação nacional, em atividades mineradoras, as organizações são obrigadas a se adequarem à Norma Regulamentadora $n^{\circ} 22$ (NR 22), específica para as empresas que desempenham atividades de mineração, que estabelece parâmetros para a melhoria das condições do ambiente laboral, reduzindo a incidência de doenças e acidentes do trabalho. Deste modo, dentre os preceitos a serem observados pelas grandes empresas mineradoras, está a implementação das medidas relativas à SSO das empresas contratadas, provendo os meios e condições para que estas realizem suas atividades em conformidade com esta Norma (Franco, Barros, Holanda \& de Souza, 2021).

Desta forma, as relações entre empresas contratantes e contratadas são estabelecidas através de exigências legais e contratuais que, normalmente, não fazem parte da rotina das pequenas empresas. Este processo condiz com a política de terceirização adotada por organizações mineradoras, que buscam a efetividade e a redução dos riscos envolvidos no processo de terceirização a partir das práticas da gestão de contratos de serviços terceirizados (Carvalho Neto \& Fernandes, 2005).

Sobre as responsabilidades das contratantes em relação às terceirizadas, Saraiva e Mercês (2013) descrevem que a Justiça do Trabalho considera que a empresa que adquire serviços será corresponsável pelas infrações praticadas pela contratada, em principal, nos âmbitos trabalhistas e previdenciário. Assim, o sistema de terceirização das mineradoras tem se desenvolvido ao longo do tempo e se apresenta como um modelo de gerenciamento rígido de contratadas, com múltiplos vínculos contratuais. A gerência de contratos destas empresas possui fiscais responsáveis por avaliar e cobrar constantemente o cumprimento de cláusulas nos contratos firmados com as suas prestadoras de serviços (Tavares, 2014).

Neste contexto, o modelo de gestão e controle do trabalho adotado afeta a estrutura organizacional das pequenas empresas prestadoras de serviços por elas não possuírem recursos econômicos, tecnológicos e humanos, o que dificulta as atividades no âmbito da Segurança e Saúde no Trabalho (Hasle \& Limborg, 2006; Boustras, Hadjimanolis, Economides, Yiannaki \& Nicolaides, 2015). Adicionalmente, como o gestor de empresa de pequeno porte tem que lidar com várias responsabilidades no nível da gestão da organização, o seu envolvimento em matérias de SSO é baixo (Hasle \& Limborg, 2006; Hasle, Limborg, Kallehave, Klitgaard \& Andersen, 2012; Zwetsloot, Drupsteen \& Vroome 2014). No entanto, outros fatores podem condicionar o desempenho de SSO nestes tipos de empresas, sendo importante compreender melhor esta questão, uma vez que se trata de uma problemática ainda pouco caracterizada, principalmente nas atividades do ramo da mineração.

Em face dessa complexidade, percebe-se que há um padrão de exigência legal a ser seguido, no entanto, cabe às empresas de pequeno porte, enquanto terceirizadas, a busca por desenvolver através das suas competências e limitações, mecanismos capazes de integrá-las e adaptá-las de forma apropriada para atender as demandas das grandes empresas.

\section{Metodologia}

$\mathrm{O}$ artigo tem como objetivo realizar uma investigação sobre a influência de uma mineradora de grande porte sobre a gestão da saúde e segurança ocupacional em uma pequena empresa. Para tanto, foi realizado um estudo de caso descritivo de caráter qualitativo, no intuito de desenvolver uma análise mais aprofundada e detalhada sobre o tema abordado (Gil, 2009). O estudo de caso foi realizado em uma empresa de pequeno porte localizada no interior do Estado de Minas Gerais que atua no ramo da mineração, fornecendo serviços de fabricação de implementos rodoviários, manutenção e higienização de veículos diversos.

A pesquisa foi dividida em três fases: coleta de dados, análise e apresentação dos resultados e redação do relatório. Na fase de coleta de dados utilizou-se uma abordagem multimétodo por meio do levantamento de documentos, observação participante com o registro de interações relacionadas à saúde e segurança, e entrevistas semiestruturadas.

Através da análise documental da contratada verificou-se o número de funcionários, segmento de atuação, faturamento anual e porte da empresa. Foram consultadas também as minutas dos contratos com os clientes, programas de saúde e segurança, relatórios e atas de reunião, a fim de avaliar a influência do fenômeno estudado quanto ao cumprimento das exigências 
contratuais. Buscou-se compreender o nível de exigência normativa da empresa contratante, avaliar os impactos no planejamento das atividades, assim como no controle de saúde e segurança da contratada antes e após a efetivação do contrato estabelecido com a mineradora.

As observações ocorreram entre janeiro e abril de 2021 e tiveram como objetivo a verificação das interações sociais e comportamentos individuais relacionados à SSO. As observações foram registradas por meio de anotações realizadas ao longo de todo o período para a posterior utilização na análise do caso.

As entrevistas semiestruturadas foram realizadas com as partes interessadas, compreendendo integrantes selecionados da empresa contratada e da mineradora. Para a contratada, entrevistou-se o gestor, a equipe administrativa e operacional, enquanto para a contratante, as perguntas foram conduzidas ao gestor do contrato. $\mathrm{O}$ critério de escolha compreendeu o tempo de empresa do entrevistado e a sua experiência na área. Os participantes da pesquisa estão relacionados no Quadro 1.

Quadro 1 - Participantes da entrevista de acordo com tempo de empresa e experiência na área.

\begin{tabular}{|l|l|l|l|l|}
\hline Empresa & Setor & Função & Tempo de empresa & Experiência na área \\
\hline Contratada & Administrativo & Gestor & 11 anos & 18 anos \\
\cline { 3 - 5 } & & Supervisor & 5 anos & 7 anos \\
\cline { 3 - 5 } & & Ger. Administrativo & 7 anos & 10 anos \\
\cline { 3 - 5 } & Recursos Humanos & 4 anos e 9 meses & 6 anos \\
\cline { 3 - 5 } & \multirow{4}{*}{ Operacional } & Lavador & 8 anos & 8 anos \\
\cline { 3 - 5 } & & Soldador & 6 anos & 22 anos \\
\cline { 3 - 5 } & & Caldeireiro & 9 anos & 30 anos \\
\cline { 3 - 5 } & & Pintor & 6 anos & 6 anos \\
\cline { 3 - 5 } & & Mecânico & 6 anos & 25 anos \\
\hline Contratante & Administrativo & Gestor de contratos & 8 anos & 8 anos \\
\hline
\end{tabular}

Fonte: Autores.

As entrevistas foram realizadas de forma individual, apresentando duração entre 1 e 2 horas. $\mathrm{O}$ roteiro de entrevista foi organizado por meio de 5 tópicos, conforme descrito no Quadro 2, ordenados de forma a criar uma linha de raciocínio para a condução dos assuntos tratados.

Quadro 2 - Tópicos da entrevista semiestruturada com os participantes.

\begin{tabular}{|c|l|}
\hline Tópico & Descrição \\
\hline 1 & Caracterização da empresa contratada. \\
\hline 2 & Histórico da prestação de serviços da contratada. \\
\hline 3 & O contrato de terceirização e as exigências de SSO para a contratada. \\
\hline 4 & Percepção de Saúde e Segurança da contratada antes e após contrato. \\
\hline 5 & O processo de gerenciamento de terceiros da empresa contratante. \\
\hline
\end{tabular}

Fonte: Autores.

Os tópicos 1 e 2 foram aplicados apenas para o gestor da empresa contratada. O primeiro visou determinar seu histórico e a sua caracterização. Buscou-se levantar as informações básicas sobre como a organização surgiu e quais seus objetivos 
estratégicos. Além disso, foi verificado como a empresa está organizada, os serviços prestados e seus locais de atuação. O segundo tópico, teve como objetivo identificar os fatores que motivaram a prestação de serviços para a organização mineradora do município. Por meio dele foi possível evidenciar as oportunidades e ameaças geradas pela parceria de negócios e ainda obter um histórico da prestação de serviços.

O terceiro tópico, direcionado aos colaboradores do setor administrativo, refere-se à formalização da relação entre o contratante e a contratada, assim como o nível de exigência do contrato sobre questões relacionadas à SSO. Foi analisado o desenvolvimento da relação de trabalho antes e após a realização do escopo do contrato. Foram abordados os procedimentos administrativos, as cláusulas do contrato, reuniões, o planejamento de ações relacionadas a SSO da contratada, fatores facilitadores, barreiras para o desenvolvimento dos trabalhos, bem como os resultados positivos e negativos obtidos.

No quarto tópico, foram envolvidos os colaboradores do setor operacional. Foi realizada uma comparação sobre as questões de SSO antes e após o contrato com a mineradora. Através das entrevistas buscou-se compreender na perspectiva dos colaboradores, quais as mudanças foram realizadas para atender ao novo cliente, assim como os pontos positivos e negativos sobre o desenvolvimento das suas atividades habituais.

No último tópico, direcionado ao gestor de contrato da mineradora, foi verificado o desenvolvimento de suas atividades no município. Buscou-se também entender os meios pelos quais é realizado o gerenciamento dos contratos com terceiros, destacando as formas de comunicação entre as partes, assim como as exigências relacionadas a SSO na prestação dos serviços. Perguntas relacionadas à expectativa de desempenho da contratada também foram realizadas nesta etapa.

A análise dos dados coletados ocorreu a partir da correlação entre o discurso do entrevistado, as práticas desenvolvidas pela organização que puderam ser observadas e os dados colhidos da análise documental. Para tal, foi realizado um processo de triangulação, envolvendo a checagem dos testemunhos coletados nas entrevistas com os documentos levantados e as observações realizadas. A triangulação possibilita uma maior validação dos resultados uma vez que permite a análise de um mesmo evento por diferentes fontes de dados (Zappellini \& Feuerschütte, 2015).

As categorias utilizadas na análise de dados foram:

- Aspectos motivadores da terceirização das atividades da empresa contratada;

- Principais fatores considerados nos processos de seleção, contratação e do prestador de serviço;

- Mudanças nas rotinas de trabalho e nos resultados da empresa contratada sobre a perspectiva da SSO;

- Principais vantagens oriundas da terceirização para a SSO;

- Principais obstáculos encontrados no processo de terceirização.

\section{Resultados e Discussão}

Através da análise de dados documentais verificou-se que a organização escolhida é uma empresa de pequeno porte composta por um quadro de 36 funcionários, sendo 10 pertencentes ao setor administrativo e 26 operacional. De acordo com o gestor da contratada a empresa foi fundada no interior de Minas Gerais, em 2010 e atua no ramo da mineração há 5 (cinco) anos, prestando serviços de fabricação de implementos rodoviários, manutenção e higienização de veículos diversos. Como prestadora de serviços terceirizados, estando estes enraizados em sua estrutura organizacional, a empresa atentou-se às oportunidades do mercado de mineração e foi contemplada em janeiro de 2021 em um processo de licitação, cujo contrato possui duração de 3 anos conforme minuta contratual.

A empresa contratante é uma mineradora de grande porte localizada no interior de Minas Gerais. De acordo com dados disponibilizados no site da própria empresa há atualmente envolvidos em suas atividades 125 mil trabalhadores, entre empregados próprios e terceiros distribuídos em várias das suas unidades espalhadas por 30 países. Com o intuito de padronizar os processos de terceirização e garantir sua aplicação de forma estratégica e legal, desde 1999 a empresa estabeleceu a sua 
política de terceirização, cabendo aos gestores de contratos monitorar se as empresas contratantes estão cumprindo as exigências contratuais.

A partir da conversa com o gestor da empresa de pequeno porte, evidenciou-se uma das variáveis significativas para a compreensão dos fatores motivadores para a prestação de serviços à mineradora.

"Há cinco anos eu venho atendendo às demandas de fabricação de implementos rodoviários, manutenção e higienização de veículos diversos. Porém, neste período minha empresa não atuava como terceirizada da organização mineradora. Estávamos no nível de subcontratada. [...]. Aquelas empresas terceirizadas não possuíam mão de obra suficiente para atender à contratante e elas nos recorria para suprir estas demandas. [...]. Foi então que a ficha caiu e percebi que minha empresa estava fazendo o trabalho daquelas que eram contratadas diretas da mineradora. [...]" (Gestor da contratada).

Esse relato esclarece a origem do interesse da pequena empresa na prestação de serviços diretos. Antes de existir um contrato entre as partes a pequena empresa de uma forma indireta já atendia as demandas da mineradora através dos serviços de subcontratação de outras empresas terceirizadas. Nos últimos dois anos há registros de 23 serviços prestados desta forma. Este fato sinalizou a oportunidade de prestação de serviços diretamente para o cliente final, mesmo que culminasse em mudanças e investimentos internos para atendimento das novas exigências contratuais.

"Quando aceitei a proposta, eu estava ciente que minha empresa precisaria se adequar aos padrões da mineradora. Entrei neste processo com a estratégia de fazer a empresa crescer em todos os sentidos. [...] Foi um risco de negócio que tive que assumir para mudar a realidade aqui dentro. [...] E, agora com esse novo contrato, consigo montar uma equipe para atender todas estas questões que eles estão pedindo[...]." (Gestor da contratada).

Foi observado que a empresa prestadora de serviço, possuía um número reduzido de empregados e muitos deles desempenhavam mais de uma função. Além disso, foram verificados setores compostos apenas por uma pessoa, como por exemplo os setores de funilaria e de pintura.

Por meio das análises das respostas dos entrevistados do setor administrativo, foi possível compreender as variáveis do processo de contratação. Com o depoimento do Gerente Administrativo, mapeou-se as etapas deste processo, tornando visível o desenvolvimento da parceria de negócios desde a oportunidade de atuação da empresa estudada até a efetivação das exigências contratuais de SSO da mineradora. A Figura 1 representa o fluxo de como ocorreu o processo de contratação.

Figura 1 - Fluxograma do processo de contratação de terceiros.
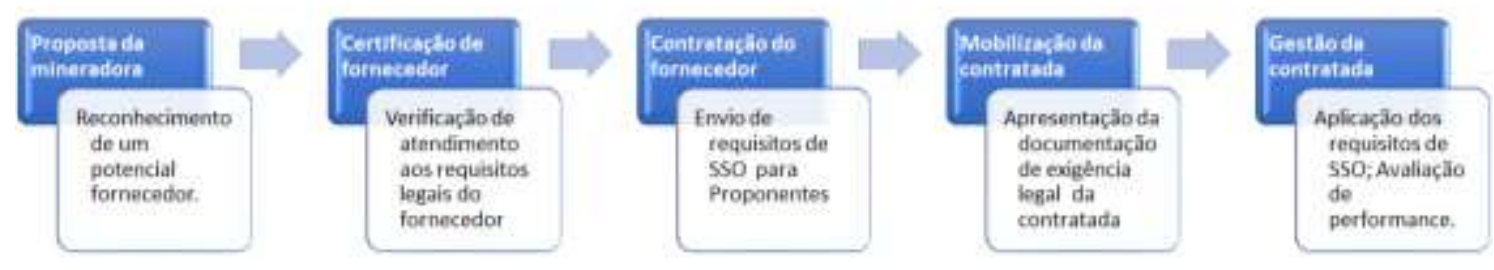

Fonte: Autores.

Evidenciou-se, por meio das entrevistas, que o processo de contratação seguiu etapas, partindo do reconhecimento dos serviços prestados pela empresa de pequeno porte, enquanto a mesma era subcontratada de empresas terceiras da mineradora. Segundo o gerente administrativo da contratada, o desempenho apresentado até aquele momento na prestação de serviços tornou a empresa um potencial fornecedor para atender às demandas com contrato direto com o cliente. Esta visibilidade permitiu à 
empresa caminhar para a etapa de certificação, em que foi observada a capacidade de atendimento de requisitos legais das empresas terceirizadas.

Quando questionado sobre o procedimento de certificação, o gerente administrativo afirmou que se trata de uma préqualificação da empresa, como observado no relato:

"Geralmente, as empresas que possuem interesse em se tornar um fornecedor da mineradora passam por um processo de certificação em que são avaliados vários requisitos, dentre eles o de Saúde e Segurança e Meio Ambiente (SSMA), que é uта pré-qualificação. Aquelas que atendem aos requisitos mínimos são cadastradas no banco de dados, aguardando avaliação. No nosso caso, especificamente, fomos reconhecidos e a partir disso recebemos a proposta da mineradora e entramos diretamente na fase de contratação." (Gerente Administrativo da contratada).

Uma particularidade relevante observada no processo de contratação foi o reconhecimento de experiências anteriores. Observou-se que as exigências documentais não foram quesitos de pré-qualificação, mas sim a referência na prestação de serviços, fazendo com que a empresa avançasse na etapa de contratação.

Em resposta ao questionamento sobre uma possível reunião antecedente à contratação, o Gerente Administrativo informou que o Gestor de Contratos da contratante realizou um encontro virtual onde foram expostas as demandas da mineradora. Acrescentou que houve esclarecimento quanto às cláusulas do contrato relacionadas ao cumprimento dos prazos e entrega do produto, deixando as exigências de Saúde e Segurança Ocupacional para serem enviadas em um segundo momento diretamente ao profissional de segurança da empresa contratada. Com isso, percebeu-se que as exigências de SSO não foram analisadas prioritariamente antes do fechamento do contrato pelas partes interessadas. Isso implicou na contratação sem uma análise prévia dos impactos relacionados à saúde e segurança.

Assim como em várias pequenas empresas no Brasil, não existia na prestadora de serviços um Serviço Especializado em Engenharia de Segurança e Medicina do Trabalho (SESMT). Todo atendimento legal relacionado a SSO até o primeiro contrato direto com a mineradora era realizado por uma consultoria especializada. Conforme documentos analisados, essa era responsável pela elaboração do Programa de Controle Médico e de Saúde Ocupacional (PCMSO), Programa de Prevenção de Riscos Ambientais (PPRA), listas de presença em Diálogos Mensais de Segurança (DMS) e treinamentos de uso correto do Equipamentos de Proteção Individual (EPI) e Segurança em Máquinas. Embora cumpridos alguns requisitos legais, através da análise dos programas e da observação das atividades desenvolvidas pelos trabalhadores, foi evidenciado que os riscos foram tratados de forma superficial nos documentos e o conteúdo não retratava toda a realidade das exposições.

Observou-se que as atividades como trabalho à quente, pintura, movimentação de cargas, trabalho em altura, assim como a montagem e desmontagem de equipamentos pesados não possuíam inspeção preliminar, Análise Preliminar de Risco (APR), permissão de trabalho, avaliações ambientais, registro de manutenção dos equipamentos e demais ações necessárias para sua realização. No entanto, constatou-se que a empresa possuía controle de registro de EPI e atendia a periodicidade de troca. Além disso, realizava a instrução dos colaboradores quanto à guarda e conservação dos equipamentos de proteção.

Identificou-se também que os itens referentes à SSO se encontravam em anexo à minuta do contrato enviado pelo Gestor da empresa mineradora e apresentavam exigências de documentos legais e gerenciamento da segurança do trabalho na empresa. Os itens exigidos foram:

- Evidências dos programas: Programa de Gerenciamento de Riscos (PGR), PCMSO e Laudos técnicos;

- Monitoramento da saúde ocupacional;

- Levantamento dos Perigos e Riscos presentes nas atividades;

- Cumprimento dos requisitos legais da NR 22;

- Auditorias internas (verificação de conformidades de procedimentos); 
- Realização de treinamentos, diálogos de Segurança e campanhas;

- Criação de indicadores de segurança;

- Elaboração do inventário dos riscos em máquinas e equipamentos;

- Instrução de trabalho para atividades críticas;

- Implantação de registro de quase acidentes;

- Aplicação de lista de verificação;

- Cronograma de ação preventiva.

Em relação aos documentos disponíveis e ao relato do gestor da pequena empresa, antes do fechamento do negócio com a mineradora, apenas 30\% das exigências de SSO do contrato estavam sendo cumpridas. Importante ressaltar que grande parte destas exigências contratuais são itens normativos referentes à legislação nacional brasileira e que a contratante demanda de requisitos e ações de gerenciamento mais rigorosas do que o estabelecido pela lei. Mesmo assim, de acordo com o gestor da pequena empresa, a contratante permitiu que o contrato fosse firmado entre as partes, com a condição de que no início das atividades todos os requisitos referentes a SSO seriam apresentados. A contratada, ao verificar que a consultoria de saúde e segurança não conseguiria atender a todas as demandas, decidiu ampliar seu quadro de colaboradores e admitiu um analista de SSO. O gestor considerou que a presença permanente deste profissional nas atividades desenvolvidas seria fundamental para o cumprimento dos requisitos e manutenção da parceria com o seu novo cliente.

A entrada do Analista de Saúde e Segurança Ocupacional deu início a um processo de mudança cultural de SSO empresa. Observou-se que nem toda a equipe compreendia as exigências e também não estava preparada para as mudanças que aconteceriam após a efetivação do contrato.

Dificuldades no processo de terceirização foram observadas. Percebeu-se que nos primeiros meses houve certa resistência por parte da equipe administrativa para o cumprimento de vários requisitos contratuais, mesmo sabendo que a empresa não estava sendo dispensada de cumpri-los. Isso pode ter sido motivado devido à fase de contratação ter sido concluída antes da fase de certificação do prestador de serviço. Assim, as exigências foram sendo atendidas com o contrato já em andamento, ou seja, não houve barreiras contratuais que impediam o início dos serviços, mas problemas administrativos que foram sendo solucionados conforme curso do contrato. Como exemplo, pode-se destacar a organização documental, o acesso às informações financeiras anteriormente centralizadas no gestor, as quais foram repassadas para a equipe administrativa e a capacitação de colaboradores administrativos quanto às etapas do processo de mobilização.

Os documentos de SSO também foram um ponto crítico e de destaque pelos gestores, tanto pela contratante quanto pela contratada. De um lado, a contratada criticava a necessidade de elaboração de muitos documentos e da modificação dos padrões corporativos, já que foge à sua realidade. De outro, a contratante exigia que a contratada se adaptasse para alcançar os objetivos contratuais. Os prazos para o atendimento dos requisitos contratuais relacionados à SSO foram vinculados à continuidade da prestação de serviços pela empresa terceirizada. Enquanto o contratante entendia que um mês era mais do que suficiente para uma empresa apresentar as evidências de uma gestão de saúde e segurança, para a pequena empresa esse prazo significava planejar, implantar e colher resultados de atividades que nunca existiram.

Ao longo do contrato, as documentações referentes a SSO tinham prazo para serem encaminhadas ao cliente, ações preventivas e corretivas de segurança precisavam ser evidenciadas em um plano de ação. Tal fato, impedia que situações de riscos detectadas no ambiente de trabalho fossem esquecidas ou negligenciadas pela empresa. No entanto, em alguns casos as ações para mitigação do risco trouxeram inicialmente resistência e insatisfação dos trabalhadores. Um exemplo observado se deu quando foi apontado que seriam necessárias mudanças estruturais para atender as exigências, como por exemplo a mudança do layout da empresa com a implantação da rota segura, que impunha aos trabalhadores uma nova forma de transitar pelas áreas. Antes, para o acesso a diferentes setores, os trabalhadores atravessavam o pátio em linha reta entre veículos e equipamentos, o 
que os expunha frequentemente a riscos de acidentes. Com a implantação da rota, as vias e passeios foram mapeados, assim apesar de tornar o deslocamento mais seguro ele também ficou mais longo e, portanto, tal fato trouxe uma relutância por parte da equipe. Apesar da resistência, após um mês de treinamento de adequação os colaboradores já estavam praticando as rotas de forma espontânea.

Em relação a equipe operacional houve resistência em manter os procedimentos e rotinas com segurança, pois se tratava de algo novo e que de certa forma impedia algumas práticas comuns desenvolvidas pelos próprios trabalhadores na execução de suas tarefas, como utilização correta dos EPIs, preenchimento da APR, sinalização do local para atividade crítica e organização do posto de trabalho ao final do expediente. Para isso, foi necessário implantar uma fiscalização e cobrança constante da adequação às novas práticas.

Antes do contrato, os trabalhadores relataram que existia um modo estruturado, porém informal de execução das atividades, o qual era repassada dos colaboradores mais antigos para os novatos. As práticas de atividades seguras não eram contempladas nesta forma de treinamento e capacitação. Embora não tenham sido encontrados registros de acidentes e doenças ocupacionais nos documentos avaliados, não é possível avaliar os resultados destas exposições aos riscos, já que em períodos anteriores a empresa não adotava registros de acidentes, quase-acidentes e auditorias de SSO. Os trabalhos do profissional de saúde e segurança foram importantes para a implantação das práticas de segurança do trabalho na rotina das atividades, para o entendimento e aceitação dos procedimentos pelos trabalhadores. O envolvimento da equipe na construção dos métodos seguros e nos controles permitiu mudanças efetivas dentro da empresa e não apenas o cumprimento de normas através da elaboração de documentos.

A partir das entrevistas com os colaboradores do setor operacional, foi possível compreender que houve mudanças significativas na execução das atividades e rotinas dentro da empresa e como elas foram percebidas pelos trabalhadores.

"Antes a gente não era vigiado, fazíamos nosso serviço sem instruções, permissões de trabalho, [...]. Agora a gente tem regras até para andar na área operacional. Todos os dias tem uma conversa de segurança. [...]. Mudou nosso jeito de trabalhar, colocou procedimentos que parecem uma receita de bolo." (Soldador da contratada).

Outra variável desta influência surgiu através da entrevista com o colaborador com mais tempo de empresa, destacando incômodo pela perda de autonomia na realização das suas atividades e pontos positivos do novo contrato:

"Quando iniciei aqui, nós não trabalhávamos para a mineradora, não tinha essa burocracia. [...]. Ninguém nos fiscalizava, não tínhamos que falar em qual etapa nosso serviço estava, não tinha supervisor. [...]. A gente controlava nossa rotina e dava certo [...]. Com esse contrato, muita coisa melhorou, [...], nosso salário, benefícios, café da manhã, almoço e café da tarde. [...]." (Caldeireiro da contratada).

Por meio desse relato, compreendeu-se as mudanças relacionadas à gestão da empresa como melhorias organizacionais e administrativas. Por outro lado, evidenciou-se o controle da atividade, implantação de procedimentos, criação da supervisão de área, melhoria das condições dos trabalhadores. Somando a estes pontos, um dos entrevistados ressaltou a influência deste contrato na empresa conforme relatado:

"Com esse contrato, tivemos que ficar mais espertos com as novas regras. Tem um uma pessoa da segurança do trabalho nos orientandos, se preocupando com nossa segurança. [...]. Antes nem me preocupava com os riscos da atividade e agora penso sempre antes de fazer qualquer atividade. [...] Mas, também ficamos engessados, não podemos fazer mais as coisas como fazíamos sem esse contrato. [...]. Tudo é controlado, [...], horário de entrada e saída, a forma que fazemos as atividades, se estamos usando os EPIs corretos, tudo [...]." (Lavador da contratada). 
De acordo Gonçalves Filho, Andrade e Marinho (2011). às questões culturais podem se transformar em entraves ou obstáculos consideráveis para as mudanças requeridas quando da implementação de Sistemas de Gestão de Saúde e Segurança no Trabalho. A falta de maturidade nas ações e aspectos relacionados à saúde e segurança no trabalho são determinantes para a formação da percepção dos trabalhadores em relação às mudanças propostas. O contrato com a grande empresa intensifica significativamente a exposição ao risco. Foi preciso informar aos trabalhadores de que as atividades seriam semelhantes, mas o volume delas aumentaria, os prazos seriam menores e que o contrato com o novo cliente envolveria diversas atividades críticas que não existiam antes como o acesso a espaços confinados e uso de novas ferramentas que também não eram utilizadas. Então há uma expectativa de que com a evolução da cultura de segurança e a partir das experiências vividas com as novas demandas de atividades, o desconforto inicial sentido pelos trabalhadores seja atenuado.

Os diálogos diários de segurança tornaram-se parte da rotina de trabalho e deram voz e visibilidade aos colaboradores, desenvolvendo o trabalho coletivo e a comunicação interna. Os temas passaram a ser sugeridos por alguns dos envolvidos, evidenciando a conquista da equipe quanto à percepção dos riscos e situações críticas. Com os relatos de quase acidentes por parte dos colaboradores, criou-se um comitê de gestão de riscos com a participação do gestor, supervisor, engenheiro mecânico, projetista, recursos humanos e analista de SSO. Esta equipe tornou-se responsável pelos tratamentos das inconformidades e busca de melhorias contínuas para a empresa.

Desta forma, pendências que, anteriormente ao contrato, eram comuns na empresa como descentralização documental, ausência do monitoramento de exames ocupacionais, treinamentos somente após início das atividades, entre outros, foram sanadas através da implantação de um sistema de gestão de saúde e segurança interno.

De acordo com o Gestor de Contrato da mineradora no tocante às expectativas da organização antes do contrato, a empresa buscava um fornecedor que atendesse as demandas, prestando um serviço de excelência. Neste contexto, a empresa contratada tornou-se reconhecida através da qualidade na prestação de seus serviços, sendo este fator um dos principais no processo decisório sobre a contratação.

\footnotetext{
"Nós estávamos buscando um fornecedor há algum tempo e não encontrávamos um que nos atendesse da forma desejada e acreditasse nos mesmos princípios que nós. Quando identificamos o tipo de serviço prestado por esta empresa, vimos um potencial fornecedor. Sabíamos que teríamos que ajustar alguns pontos, mas visualizamos o resultado. [...]". (Gestor Fiscal de contratos da contratante).
}

O entrevistado informou também que fez parte da política da gestão de contratos o acompanhamento das empresas terceirizadas e que esta proximidade com o fornecedor, dita como essencial pela mineradora, possibilitou alcançar os objetivos de ambas as partes. Verificou-se que a proximidade estava diretamente relacionada ao monitoramento e exigência de cumprimento de prazos e requisitos, assim como a entrega dos serviços no padrão da contratada. Observou-se que diante das dificuldades enfrentadas pela pequena empresa, quando do atendimento às exigências de SSO, a contratada se manteve inflexível com os prazos. Não houve nenhum programa de auxílio ou desenvolvimento de parceiros nesta temática, o que tornou o processo mais difícil para a pequena empresa, já que são realidades distintas.

Embora a mudança da cultura de segurança dentro da pequena empresa tenha ocorrido de forma compulsória, o contrato com a mineradora possibilitou melhorias importantes em toda organização, como por exemplo a seleção de novos colaboradores tanto do setor operacional quanto do administrativo. Era necessário pessoal qualificado para o melhor desempenho das atividades e o contrato de terceirização possibilitou a capacitação e contratação de novos trabalhadores, já com melhorias no processo de admissão por parte da equipe administrativa.

Evidenciou-se novos investimentos por meio da aquisição de equipamentos e outros recursos em todos os setores da empresa. Fato este corroborado pelo gestor da empresa quando questionado. Ele informou ainda que houve um aumento 
expressivo no faturamento da empresa, mas não soube dizer se parte desse aumento tem alguma relação direta ou indireta com alguma mudança das práticas de SSO implementadas.

Uma grande vantagem do processo de terceirização da empresa em relação a SSO está relacionada ao padrão de exigência do contrato com o cliente. Este padrão levou à contratação de um profissional qualificado, bem como à melhorias na qualidade dos documentos, programas e práticas de segurança do trabalho. É notório que o desenvolvimento de um setor de SSO trouxe ganhos para a empresa como todo. Isso pode ser observado por meio de fatores como: a satisfação dos trabalhadores em relação a melhoria dos benefícios recebidos; a melhoria nos controles de riscos com redução da probabilidade de paradas de atividades e perdas inesperadas; a ampliação das práticas e controles para atendimento de serviços a outros clientes; e o aumento da visibilidade da empresa para prestação de serviços no ramo da mineração.

A empresa contratada buscou cumprir todas as suas responsabilidades motivadas pelas exigências contratuais, o que refletiu na melhoria de diversas áreas administrativas e operacionais, na gestão estratégica da empresa como um todo. Isso demonstrou que o desenvolvimento da gestão de saúde e segurança também tem a capacidade de entregar valor. A pressão pela conformidade dos requisitos do cliente determinou as escolhas e prioridades adotadas na gestão da empresa contratada. Embora grandes empresas tenham realidades diferentes de pequenas e médias empresas na perspectiva da SSO, a organização e as práticas seguras podem oferecer a todas uma oportunidade de melhorar o seu desempenho institucional. Essas podem estabelecer uma revisão sistemática dos seus processos com eliminação ou atenuação de riscos, aumento da confiança dos seus clientes e redução das probabilidades de ocorrência de situações indesejadas, além da tomada de decisões a partir de dados reais.

Outra evidência encontrada a partir dos resultados é que, embora o desenvolvimento da gestão de saúde e segurança no trabalho tenha trazido resultados importantes percebidos pelos colaboradores, não houve dados suficientes para afirmar que as melhorias de SSO no ambiente de trabalho impactaram nos aspectos financeiros dos negócios, apesar de existirem suposições que tais práticas podem levar à melhoria de desempenho.

Ainda que tenham sido observadas dificuldades para a pequena empresa com sua estrutura limitada, o gestor da contratada reconhece que prestar serviços terceirizados para a mineradora com a devida incorporação de práticas de gestão de SSO foi importante. Esse processo trouxe proximidade, reputação e destaque para toda a sua cadeia de valor. A literatura aponta que empresas que possuem um capital reputacional fortalecido, possibilitam ganhos em sua capacidade de negociar contratos mais atraentes com fornecedores, de cobrar preços melhores para seus produtos e reduzir seus custos (MOYSES FILHO et al, 2010). Após a fase mais crítica do início do contrato e cumprimento das cláusulas iniciais, a empresa ampliou a sua prestação de serviços para outras quatro unidades operacionais da mineradora e a nova gestão de SSO foi incorporada para todos os demais contratos da empresa. Isso revelou uma influência positiva da empresa contratante sobre a gestão de saúde e segurança da prestadora de serviços.

\section{Conclusão}

O presente trabalho propôs investigar e descrever a influência da organização mineradora na gestão de saúde e segurança ocupacional da empresa de pequeno porte prestadora de serviços. Com a análise das entrevistas, observações e dos documentos, foi possível notar que a prestação de serviços para a empresa mineradora trouxe mudanças para a realidade da empresa contratada. Além de proporcionar a criação de um setor de saúde e segurança do trabalho com a contratação de um Analista de SSO, iniciouse o desenvolvimento de uma cultura organizacional prevencionista atuante por todos os setores da empresa e com a ampla participação dos colaboradores. A implementação dos requisitos de segurança do cliente inicialmente trouxe relutância por parte dos colaboradores. Entretanto, os meios adotados para a adequação ao contrato e implementação dos requisitos de SSO, utilizando-se do envolvimento da equipe, permitiu um avanço relevante. Este avanço se refletiu na adequação à legislação relacionada à saúde e segurança, na implementação de um sistema de gestão de SSO e em melhorias nos processos. 
Sobre os impactos positivos desse novo contrato na empresa, evidenciou-se que as adequações para atender as exigências da contratante contribuíram para uma maior maturidade das práticas de segurança. Essas por sua vez passaram a permear questões como novos investimentos e a expansão do contrato para outras regiões de atuação da organização mineradora.

Observou-se também que as estratégias da empresa se direcionam para o atendimento exclusivo dos interesses de um único cliente. Este fato mostrou-se relevante, evidenciando que a influência da mineradora supera preocupações com requisitos legais e influencia diretamente na saúde e segurança dos colaboradores da contratada, sendo esta preocupação maior do que preceitos legais estabelecidos no país. Isso pode ser notado devido às mudanças internas, investimentos e alteração do comprometimento com a SSO, que só foram possíveis devido às adequações de exigências contratuais da mineradora.

Por fim, é importante destacar como limitação do estudo a própria natureza da pesquisa realizada. Por se tratar de um caso único, este não permite uma generalização metodológica para todas as empresas terceirizadas de pequeno porte do ramo da mineração ou demais ramos de atividade. No entanto, embora não seja possível generalizar, abre espaços para discussão e novos estudos que busquem compreender de maneira mais ampla como a sua problemática se dá em outras empresas do ramo.

\section{Referências}

Arocena, P., \& Núñez, I. (2010). An empirical analysis of the effectiveness of occupational health and safety management systems in SMEs. International small business journal, 28(4), 398-419.

Boustras, G., Hadjimanolis, A., Economides, A., Yiannaki, A., \& Nicolaides, L. (2015). Management of health and safety in micro-firms in Cyprus-Results from a Nationwide Survey. Safety science, 79, 305-313.

Carvalho Neto, A. M., \& Fernandes, B. (2005). As práticas gerenciais frente aos principais desafios apontados pelas maiores empresas brasileiras na gestão de terceirizados. Anais do Encontro Nacional de Pós-Graduação e Pesquisa em Administração-EnANPAD.

Ceribeli, H. B., \& Lima, T. C. B. (2019). Terceirização em uma organização do setor de mineração. Interface-UFRN/CCSA ISSN Eletrônico 2237-7506, 16(1), $27-50$.

Costa, D. D. C. D., \& Menegon, N. L. (2008). Condução de ações em saúde e segurança do trabalho em pequenas e médias empresas: análise de três casos. Revista Brasileira de Saúde Ocupacional, 33, 60-71.

de Magalhães, Y. T., de Carvalho Neto, A. M., \& Gonçalves, P. P. B. (2010). Os múltiplos desafios da gestão de terceirizados: a experiência dos gestores de contratos. Revista de Ciências da Administração, 116-143.

Franco, R., de SC Barros, M. L., Holanda, C. C., \& de Souza, J. C. (2021). A importância da segurança e saúde ocupacional no setor mineral. Brazilian Journal of Development, 7(5), 50549-50561.

Guerra, O., \& Teixeira, F. (2010). A sobrevivência das pequenas empresas no desenvolvimento capitalista. Brazilian Journal of Political Economy, 30, 124139.

Gil, A. C. (2009). Estudo de caso. Atlas.

Gonçalves Filho, A. P., Andrade, J. C. S., \& Marinho, M. M. D. O. (2011). Cultura e gestão da segurança no trabalho: uma proposta de modelo. Gestão \& Produção, 18, 205-220.

Hasle, P., \& Limborg, H. J. (2006). A review of the literature on preventive occupational health and safety activities in small enterprises. Industrial health, 44(1), $6-12$.

Hasle, P., Limborg, H. J., Kallehave, T., Klitgaard, C., \& Andersen, T. R. (2012). The working environment in small firms: Responses from owner-managers. International Small Business Journal, 30(6), 622-639

King, W. R. (2005). Outsourcing becomes more complex. Inf. Syst. Manag., 22(2), 89-90.

Magalhães, Y. T., Ferreira, A. M. D. G., Saraiva, L. A. S., \& Brasil, E. R. (2009). Competências necessárias e competências exercidas na gestão de contratos de serviços terceirizados em uma empresa do setor de mineração de Minas Gerais.

Rabelo, M. F. F. (2014). A influência da atividade mineradora sobre as estratégias das micro e pequenas empresas (Doctoral dissertation, Mestrado em Administração).

Saraiva, L. A. S., \& da Silva, M. A. (2020). A decisão de terceirizar ou primarizar: Um estudo de caso em uma mineradora. Destarte, 2 (2), 75-94.

Saraiva, L. A. S., \& das Mercês, R. E. (2013). Terceirização na gestão da manutenção: estudo de caso de uma mineradora. Revista de Administração da UNIMEP, $11(1), 1-24$

Tavares, P. S.(2014). O processo de terceirização na Vale e os relatórios de sustentabilidade: uma análise a partir da metodologia do global reporting initiative. Estado, Sistemas Produtivos e Populações Tradicionais, 375. 
Research, Society and Development, v. 10, n. 9, e22010917975, 2021

(CC BY 4.0) | ISSN 2525-3409 | DOI: http://dx.doi.org/10.33448/rsd-v10i9.17975

Zappellini, M. B., \& Feuerschütte, S. G. (2015). O uso da triangulação na pesquisa científica brasileira em administração. Administração: ensino e pesquisa, 16(2), 241-273

Zwetsloot, GI, Drupsteen, L., \& de Vroome, EM (2014). Segurança, confiabilidade e satisfação do trabalhador durante a mudança organizacional. Journal of Loss Prevention in the Process Industries, $27,1-7$. 